\title{
Influence of Inhaled Corticosteroids on Community-acquired Pneumonia in Patients with Bronchial Asthma
}

\author{
Masako To, Yasuo To, Hirokazu Yamada, Chuhei OgAwA, \\ Mamoru OTOMO, Naohito SUZUKI and Yasuyuki SANO
}

\begin{abstract}
Objective The aim of the present study was to evaluate the influence of inhaled corticosteroids (ICS) on community-acquired pneumonia (CAP) in patients with asthma.

Patients and Methods All asthmatic patients who required hospitalization for CAP from the beginning of 1989 through December 2001 were enrolled in this retrospective study. Patients who used oral corticosteroids daily were excluded. Patients were divided into two groups based on whether or not they used ICS, and we analyzed clinical characteristics of the pneumonia. Sixtytwo patients ( 28 males, 34 females; mean age, 54.5 years) were enrolled in this study. Thirty-seven of 62 patients used ICS, with the mean dosage being $777.9 \mu \mathrm{g} / \mathrm{day}$.

Results We found no significant differences between the two groups with regard to mean age, serum albumin level, duration of asthma, pulmonary function and frequency of intravenous infusion of corticosteroids in the outpatient department. There were no significant differences in body temperature, white blood cell count, and CRP value upon admission between the two groups. Differences were not significant in the period of resolution of the pneumonia or in the frequency of pathogens identified between the two groups.

Conclusion ICS therapy appears to have no influence on CAP in patients with asthma. We recommend that ICS should be continued to control asthma with adequate antibiotic therapy when asthmatic patients have CAP. (Internal Medicine 43: 674-678, 2004)
\end{abstract}

Key words: bronchial asthma, community-acquired pneumonia, inhaled corticosteroid, microorganism, resolution period of pneumonia

\section{Introduction}

Inhaled corticosteroids (ICS) are the most effective therapy for asthma currently available and have been used in such patients with few systemic side effects. However, their influence on community-acquired pneumonia (CAP) has not been well established.

A few authors have reported the influence of ICS on respiratory tract infections (1-5). These reports contain not only patients with CAP but also many patients with acute bronchitis. The influence of ICS on CAP is not precisely clarified.

We investigated the clinical characteristics of pneumonia in asthmatic patients who did and did not use ICS. The aim of the present study was to evaluate the influence of ICS on CAP pneumonia in patients with asthma.

\section{Methods}

\section{Patients}

All asthmatic patients who required hospitalization for community-acquired pneumonia from the beginning of 1989 through December 2001 were enrolled in this retrospective study. Patients who used oral corticosteroids daily were excluded, as were those with chronic bronchitis, chronic obstructive pulmonary disease (COPD) or bronchiectasis, those who were immunocompromised or who had a malignant disease. Patients were divided into two groups based on the use of ICS, and we analyzed the clinical characteristics of their pneumonia. Patients with ICS had used ICS at least for 3

From the Department of Allergy and Respiratory Medicine, Doai Memorial Hospital, Tokyo

Received for publication May 6, 2003; Accepted for publication March 2, 2004

Reprint requests should be addressed to Dr. Naohito Suzuki, the Department of Allergy and Respiratory Medicine, Doai Memorial Hospital, 2-1-11 Yokoami Sumida-ku, Tokyo 130-8587 
Influence of ICS on Pneumonia

Table 1. Characteristics of Patients at Admission

\begin{tabular}{cccc}
\hline & $\begin{array}{c}\text { with ICS } \\
(\mathrm{n}=37)\end{array}$ & $\begin{array}{c}\text { without ICS } \\
(\mathrm{n}=25)\end{array}$ & $\mathrm{p}$ \\
\hline ICS (equivalent doses of BDP) & $777.9 \pm 315.6$ & $0.0 \pm 0.0$ & \\
\hline$(\mu \mathrm{g} / \mathrm{d})$ & & & \\
\hline Sex & Male 18, Female 19 & Male 10, Female 15 & $\mathrm{NS}$ \\
Age $(\mathrm{y})$ & $53.2 \pm 17.2$ & $56.4 \pm 21.6$ & $\mathrm{NS}$ \\
\hline Serum albumin $(\mathrm{mg} / \mathrm{dl})$ & $4.00 \pm 0.35$ & $3.81 \pm 0.49$ & \\
\hline
\end{tabular}

ICS: inhaled corticosteroid, BDP: beclomethasone dipropionate.

Table 2. Characteristics of Asthma

\begin{tabular}{cccc}
\hline & $\begin{array}{c}\text { with ICS } \\
(\mathrm{n}=37)\end{array}$ & $\begin{array}{c}\text { without ICS } \\
(\mathrm{n}=25)\end{array}$ & $\mathrm{p}$ \\
\hline Duration of asthma $(\mathrm{y})$ & $11.6 \pm 9.8$ & $12.2 \pm 18.6$ & $\mathrm{NS}$ \\
FEV1 $(l)$ & $2.40 \pm 0.83$ & $2.07 \pm 1.03$ & $\mathrm{NS}$ \\
FEV1\% $(\%)$ & $81.1 \pm 11.9$ & $80.9 \pm 9.1$ & $\mathrm{NS}$ \\
$\begin{array}{c}\text { Frequency of CS intravenous infusion } \\
\text { in outpatient department (previous year) }\end{array}$ & $2.0 \pm 2.8$ & $1.0 \pm 1.4$ & $\mathrm{NS}$ \\
\hline
\end{tabular}

ICS: inhaled corticosteroid, CS: corticosteroids, FEV1:forced expiratory volume in 1 second.

months before admission. Patients without ICS had never used ICS before admission.

Asthma was diagnosed according to the Guideline of Global Initiative for Asthma (6). COPD was diagnosed referring to the Global Initiative for Chronic Obstructive Lung Disease (7). The definition of CAP was based on the definition used in the article by Ishida et al (8). Patients who met three of following criteria, including the 1), were diagnosed as having pneumonia: 1) infiltrates on chest X-ray, 2) body temperature over $37^{\circ} \mathrm{C}$ within 24 hours of admission, 3) production of purulent sputum, 4) C-reactive protein (CRP) value greater than $0.4 \mathrm{mg} / \mathrm{dl}$, and 5) white blood cell count higher than $9,000 / \mu 1$. In this article, 4 ) is add to the definition used in the article by Ishida et al (8) because some old patients with CAP show normal value of white blood cell count and high CRP value. Patients were excluded from this study when the above-mentioned abnormalities were attributed to another cause such as chronic inflammatory lung disease, collagen vascular disease and so on. Those with tuberculosis and atypical mycobacteriosis were excluded. Patients with atypical pneumonia were excluded because of technical limitations of the examination. The resolution period was defined as the period from admission to the time when the body temperature, white blood cell counts and CRP value decreased to normal range.

\section{Identification of pathogens}

When specific organisms were isolated from sputum, blood or pleural effusion and compatible with the clinical course, they were considered as pathogens. Organisms isolated before manifestation of pneumonia were considered to have been colonized.

\section{Statistical analysis}

Results were expressed as mean \pm SD. Differences between the two groups were compared using Mann-Whitney's U test, the Chi square test or one-way ANOVA. $p<0.05$ was considered to be significant. All data were analyzed using StatView J-4.5 (Abacus Concepts, Inc., Berkeley, CA).

\section{Results}

Sixty-two patients were enrolled in this study. The mean age of the total study population was 54.5 years (range 1683 ), and 28 were male and 34 female. Thirty-seven of the 62 patients used ICS and 25 did not. Mean dose of ICS was $777.9 \mu \mathrm{g} / \mathrm{day}$ with a range of $200-1,600 \mu \mathrm{g} / \mathrm{day}$ in the patients who used ICS. All patients had mild to moderate asthma.

As shown in Table 1, the mean age and serum albumin level did not differ significantly between the two groups. Table 2 shows characteristics of their asthma. Pulmonary function tests had been performed within 1 year before admission. No significant differences were observed in the duration of asthma, pulmonary function and frequency of intravenous infusion of corticosteroids in the outpatient department.

With regard to the clinical characteristics of pneumonia, 
To et al

Table 3. Clinical Characteristics of Pneumonia in Study Subjects

\begin{tabular}{cccc}
\hline & $\begin{array}{c}\text { with ICS } \\
(\mathrm{n}=37)\end{array}$ & $\begin{array}{c}\text { without ICS } \\
(\mathrm{n}=25)\end{array}$ & $\mathrm{p}$ \\
\hline Body temperature $\left({ }^{\circ} \mathrm{C}\right)$ & $37.8 \pm 1.0$ & $37.6 \pm 1.1$ & $\mathrm{NS}$ \\
WBC $(/ \mu \mathrm{l})$ & $11,530 \pm 4,187$ & $10,156 \pm 4,124$ & $\mathrm{NS}$ \\
$\mathrm{ESR}(\mathrm{mm} / \mathrm{h})$ & $52.9 \pm 33.1$ & $63.0 \pm 33.9$ & $\mathrm{NS}$ \\
$\mathrm{CRP}(\mathrm{mg} / \mathrm{dl})$ & $12.2 \pm 7.5$ & $12.2 \pm 9.0$ & $\mathrm{NS}$ \\
Resolution period $(\mathrm{d})$ & $10.8 \pm 4.0$ & $11.0 \pm 4.0$ & $\mathrm{NS}$ \\
\hline
\end{tabular}

ICS: inhaled corticosteroid, WBC: white blood cells, ESR: erythrocytes sedimentation rate, CRP: C-reactive protein.

Table 4. Frequency of Pathogens Detected in Sputum, Blood or Pleural Effusions

\begin{tabular}{ccc}
\hline \multirow{2}{*}{ Organism } & \multicolumn{2}{c}{ Percent of episodes (\%) } \\
\cline { 2 - 3 } & with ICS $(\mathrm{n}=37)$ & without ICS $(\mathrm{n}=25)$ \\
\hline Streptococcus pneumoniae & 32.4 & 32.0 \\
Haemophilus influenzae & 5.4 & 8.0 \\
Staphylococcus aureus & 0.0 & 4.0 \\
Klebsiella pneumoniae & 5.4 & 5.0 \\
unknown & 56.8 & 52.0 \\
\hline
\end{tabular}

ICS: inhaled corticosteroid. Chi-square test: NS ( $>>0.05)$.

Table 5. Clinical Characteristics of Pneumonia in ICS Subjects

\begin{tabular}{ccccc}
\hline & $\begin{array}{c}<00 \mu \mathrm{g} / \mathrm{day} \\
(\mathrm{n}=8)\end{array}$ & $\begin{array}{c}800 \mu \mathrm{g} / \mathrm{day} \\
(\mathrm{n}=18)\end{array}$ & $\begin{array}{c}>800 \mu \mathrm{g} / \mathrm{day} \\
(\mathrm{n}=11)\end{array}$ & $\mathrm{p}$ \\
\hline Body temperature $\left({ }^{\circ} \mathrm{C}\right)$ & $37.9 \pm 0.8$ & $37.8 \pm 1.3$ & $37.4 \pm 0.6$ & $\mathrm{NS}$ \\
WBC $(/ \mu \mathrm{l})$ & $11,390 \pm 3,458$ & $12,088 \pm 4,652$ & $11,066 \pm 4,547$ & $\mathrm{NS}$ \\
ESR $(\mathrm{mm} / \mathrm{h})$ & $65.4 \pm 26.5$ & $49.9 \pm 39.8$ & $39.0 \pm 20.7$ & $\mathrm{NS}$ \\
CRP $(\mathrm{mg} / \mathrm{dl})$ & $13.0 \pm 7.1$ & $12.8 \pm 7.7$ & $9.1 \pm 9.8$ & $\mathrm{NS}$ \\
Resolution period $(\mathrm{d})$ & $10.5 \pm 4.1$ & $11.1 \pm 4.1$ & $11.0 \pm 5.0$ & $\mathrm{NS}$ \\
\hline
\end{tabular}

ICS: inhaled corticosteroid, WBC: white blood cells, ESR: erythrocytes sedimentation rate, CRP: C-reactive protein. Patients with ICS were divided into three groups based on the dosage of ICS.

no significant differences were observed in body temperature, white blood cell counts, and CRP values on admission between the two groups (Table 3). No significant difference was detected in the number of days required for resolution of the pneumonia (resolution period).

Streptococcus pneumoniae was the most frequently found pathogen in both groups (Table 4). No statistically significant difference was observed in the frequency of pathogens between the two groups.

Patients with ICS were divided into three groups based on the daily dose of ICS and we analyzed the clinical characteristics of their pneumonia. No significant differences were observed in body temperature, white blood cell counts, CRP values on admission, and the number of days required for resolution of the pneumonia in the three groups (Table 5).

\section{Discussion}

Influence of ICS on CAP has not been well established. Only Kobayashi and Iikura have reported a clinical study on the influence of ICS on CAP (9). They found no significant difference in the severity of pneumonia, as well as white blood cell counts and CRP values on admission, between patients with and without ICS. But there are some limitations. It is clearly described that asthmatic patients with COPD or old tuberculosis are included in their study. But the number of those patients in each group is not described. They do not clearly describe the characteristics of both groups (with or 
without ICS).

Patients with COPD or old tuberculosis more easily acquire lower respiratory infection, which is difficult to cure. Gram negative rods were detected more frequently in patients with than without chronic airway inflammation. Frequent intravenous infusion of corticosteroid may induce immunosuppression. To et al (10) reported that the frequency of common pathogens (Streptococcus pneumoniae+Haemophilus influenzae) was lower in patients with severe asthma than in patients with mild to moderate asthma.

If asthmatic patients with chronic bronchitis and associated conditions had been included, or the number of patients with severe asthma was larger in the group of patients with ICS, it is possible that factors other than ICS (severity of asthma, complicating diseases, etc.) influenced the infection.

In the present study, we strictly excluded patients in whom the above-mentioned factors might influence the clinical properties of pneumonia. Among our patients, the frequency of intravenous infusion of corticosteroid was similar between those using and not using ICS. Mean age, mean serum albumin and characteristics of asthma were also similar between those using and not using ICS.

Asthmatic patients with pneumonia only were enrolled to improve precision. In addition, no significant differences were observed in the clinical properties of pneumonia between patients with or without ICS.

The histological effects of ICS on the airway have been shown. Although thinning of the skin is well known as an adverse effect of topical steroid therapy, there is no evidence of a similar process in the airways (11). Furthermore, Laitinen et al reported that the airway epithelia of asthmatic patients recovered morphological function after a 3-month period of ICS therapy (12). Lundgren et al found no evidence of epithelial structural abnormalities in patients treated with ICS for more than 10 years (13). Thus, ICS does not seem to disturb airway epithelial function or affect the properties of airway infection.

From our results and those of the histological studies, ICS therapy appears to have no influence on community-acquired pneumonia in patients with asthma. We recommend that ICS should be continued to control asthma with adequate antibiotic therapy when asthmatic patients experience respiratory tract infection.

A limitation of the present study was its retrospective design. Various doses of ICS were used in this study $(200 \mu \mathrm{g} /$ day-1,600 $\mu \mathrm{g}$ /day). A high dose of ICS may influence the characteristics of pneumonia in patients with asthma. Our data shows that doses of ICS (less than 1,600 $\mu \mathrm{g}$ /day) does not influence body temperature, white blood cell count, CRP value on admission and the number of days required for resolution of the pneumonia.

Various antibiotics were used in the patients enrolled in this study. In this study, the majority of patients received penicillin, first or second-generation cephalosporin or macrolides. Some patients received carbapenem or new quinolones mainly because of penicillin allergy. Choice of antibiotics may influence the resolution period of pneumonia. To check this point, the patients were divided into groups based on the antibiotics used for pneumonia and we analyzed the number of days required for resolution of the pneumonia. No statistically significant difference was observed in the groups (data not shown).

Also, our method of pathogen detection has a limitation. Marston et al (14) reported results of a prospective study of the incidence of community-acquired pneumonia and they categorized patients as having "definite", "probable", or "possible" infection with a specific organism according to definitions described in the report. A few of our patients satisfied the criteria of "definite". All other patients satisfied the criteria of "possible" or "probable" according to their definition. Even if they were not "definite", they were worth considering.

A prospective study on the influence of ICS on community-acquired pneumonia may provide more precise information. However, a prospective design is difficult to implement because almost all asthmatic patients in our hospital use now ICS. Although some mild asthmatic patients (some of patients taken care by their family doctor) do not use ICS, almost all moderate or severe asthmatic patients use ICS now. Around 1989, ICS therapy was not very popular in Japan, so some patients with moderate asthma were not given ICS. For this reason, the background (patient characteristics and clinical properties of asthma) of our two groups was the same. Furthermore, the date on admission of patients in each group is variable. Thus the progress of antibiotics and diagnosis of pneumonia in 10 years do not affect the result in both groups.

Also, we strictly excluded factors that could influence the clinical properties of pneumonia. Thus, we feel that this study does provide objective information on the influence of ICS on community-acquired pneumonia in patients with asthma.

In conclusion, ICS therapy seems to have no influence on community-acquired pneumonia in patients with asthma. We recommend that ICS should be continued to control asthma with adequate antibiotic therapy when asthmatic patients have respiratory tract infection.

\section{References}

1) Watanabe $Y$, Tanaka $H$, Ogawa $T$. Influence of beclomethason dipropionate inhalation therapy on respiratory bacterial infection in patients with an asthmatic attack. Arerugi (Jpn J Allergol) 46: 1132-1135, 1997 (in Japanese, Abstract in English).

2) Toogood JH. Complications of topical steroid therapy for asthma. Am Rev Respir Dis 141: S89-S96, 1990.

3) Second report of the Brompton Hospital/Medical Research Council Collaborative Trial. Double-blind trial comparing two dosage schedules of beclomethasone dipropionate aerosol with a placebo in chronic bronchial asthma. Br J Dis Chest 73: 121-132, 1979.

4) Tarlo S, Broder I, Spence LA. Prospective study of respiratory infection in adult asthmatics and their normal spouses. Clin Allergy 9: 293 301, 1979.

5) Okimoto N, Sunagawa N, Asaoka N, et al. Influence of steroid inhala- 
tion therapy on microorganism of respiratory infections in patients with bronchial asthma. Kansenshogaku Zasshi 73: 1165-1166, 1999 (in Japanese, Abstract in English).

6) Global Initiative for asthma. Global strategy for asthma management and prevention NHLBI/WHO workshop report. NIH Publication, 2-9, 2002.

7) Global Initiative for chronic obstructive lung disease. Global strategy for the diagnosis, management and prevention of chronic obstructive pulmonary disease. NHLBI/WHO workshop report. NIH Publication, 6-9, 2001.

8) Ishida T, Hashimoto T, Arita M, Ito M, Osawa M. Etiology of community-acquired pneumonia in hospitalized patients: a 3-year prospective study in Japan. Chest 114: 1588-1593, 1998.

9) Kobayashi N, Iikura M. Bacterial pneumonia in asthmatic patients. Arerugika 13: 329-335, 2002 (in Japanese).

10) To M, To Y, Yamada H, Ogawa C, et al. Clinical properties of community-acquire pneumonia in patients with asthma. Nihon Kokyuki
Gakkai Zasshi (JJRS) 41: 89-94, 2003 (in Japanese, Abstract in English).

11) Barnes PJ, Pedersen S. Efficacy and safety of inhaled corticosteroids in asthma. Am Rev Respir Dis 148: S1-S26, 1993.

12) Laitinen LA, Laitinen A, Haahtela T. A comparative study of the effects of an inhaled corticosteroid, budesonide, and a beta 2-agonist, terbutaline, on airway inflammation in newly diagnosed asthma: a randomized, double-blind, parallel-group controlled trial. J Allergy Clin Immunol 90: 32-42, 1992.

13) Lundgren R, Soderberg M, Horstedt, Stenling R. Morphological studies on bronchial mucosal biopsies from asthmatics before and after ten years treatment with inhaled steroids. Eur Respir J 1: 883-889, 1988.

14) Marston BJ, Plouffe JF, File TM Jr, et al. Incidence of communityacquired pneumonia requiring hospitalization. Results of a populationbased active surveillance Study in Ohio. Arch Intern Med 157: 17091718, 1997. 